\title{
Artigos
}

\section{De memorias largas y cortas: \\ Poder local y violencia en el Noroeste argentino}

Ludmila da Silva Catela*

\section{Resumén}

En este texto propongo una mirada sobre las relaciones y diferencias entre dos planos de análisis al observar las memorias locales en torno a la represión política, del pasado reciente, en el noroeste argentino. Para esto a lo largo del trabajo se plantean dos niveles de comprensión sobre el tiempo: memorias largas y memorias cortas. Esta manera de mirar el pasado, desde las tensiones generadas por memorias locales sobre las memorias más encuadradas, permite descubrir las resistencias y estrategias de aquellos que portan menos capitales económicos y simbólicos para imponer sus relatos en el espacio público. Este análisis está basado en el trabajo de campo en las localidades de Tumbaya y Calilegua, donde se observan los contrastes que se producen con las representaciones y prácticas dominantes en torno a las violaciones a los derechos humanos y la memoria de la represión. Estos contrastes dan cuenta de formas particulares de hablar de la violencia que se restringe a un período corto (1976-1983) que impone, por un lado, formas de dominación simbólica sobre qué y cómo debe recordarse el pasado. Por otro lado, operan silenciando y olvidando períodos más largos y complejos, en relación a las vivencias de violencia, sus memorias y a otros actores involucrados en ellas.

\section{Palabras llaves}

Dictadura. Memorias locales. Argentina.

\section{Resumo}

Neste texto, proponho uma mirada sobre as relações e diferenças entre dois planos de análise ao observar as memórias locais sobre a repressão política do passado recente no noroeste da Argentina. Para isso, ao longo do trabalho, são propostos dois níveis de compreensão sobre o tempo: memórias longas e memórias curtas. Esta maneira de ver o passado, das tensões

* Ludmila da Silva Catela es Doctora en Antropología por la Universidade Federal do Rio de Janeiro (UFRJ). Investigadora Independiente de CONICET / IDACOR / UNC. E-mail: ludmilacatela@yahoo.es.(UFRRJ). Email: luena.ufrrj@gmail.com. 
geradas pelas memórias locais sobre as memórias mais enquadradas, permite-nos descobrir as resistências e estratégias daqueles que carregam menos capital econômico e simbólico para impor suas histórias no espaço público. Esta análise baseia-se no trabalho de campo nas localidades de Tumbaya e Calilegua, onde os contrastes que ocorrem com representações e práticas dominantes são observados em relação a violações de direitos humanos e a memória de repressão. Esses contrastes dão conta de formas particulares de falar sobre violência que é restrita a um curto período (1976-1983) que impõe, por um lado, formas de dominação simbólica sobre o que e como o passado deve ser lembrado. Por outro lado, eles operam silenciando e esquecendo períodos mais longos e mais complexos, em relação às experiências de violência, suas memórias e outros atores envolvidos neles.

\section{Palavras-chave}

Ditadura. Memórias locais. Argentina.

\section{Abstract}

This text intends to examine relations and differences of two analytical levels in order to observe local memories of political repression in Argentina's Northwest's recent past. Two levels for the understanding of time are proposed: long memories and short memories. This way of looking at the past, from tensions generated by local memories on more strictly framed memories, allows us to uncover resistences and strategies of those who have less economic and symbolic capital to impose their stories in public spaces. This analysis is based upon fieldwork in Tumbaya and Calilegua, where the contrast established against dominant representations and practices are observed in relation with human rights violations and the memory of repression. These contrasts reveal particular ways of talking about a kind of violence confined in a short period of time (1976-1983), one that imposes forms of symbolic domination on what can be remembered and how. These contrasts also operate through silencing and forgetting longer and more complex periods in their relation with violence experiences, their memories and other participants.

\section{Keywords}

Dictatorship. Local memories. Argentina.

\section{Escena I}

En los años 1872-1875 tuvo lugar un levantamiento de campesinos indígenas en las tierras altas de las provincias de Jujuy y Salta en el norte Argentino. Las características agrarias de la revuelta 
fueron un ejemplo clásico de las tensiones y conflictos entre una clase de terratenientes y comunidades campesinas. Pero este hecho tuvo una característica y un interés adicional, por primera vez en la historia latinoamericana, los rebeldes fueron acusados públicamente de "comunismo" por los voceros de la clase gobernante.

(RUTLEDGE, 1992, p.239-240).

\section{Escena II}

El 10 y 11 de febrero de 1946 han sido los días más trágicos de esta huelga que hoy entra en su cuarto día. En efecto, los huelguistas... se dirigieron a los lotes en busca de indios para largarlos al asalto..." Hoy la situación siguió con un impresionante desfile. Se veía un panorama similar a los carnavales pues los indios con sus raros atavíos y sus adornos parecían más fantasía que realidad. Ahora se teme de un momento a otro que se asalte a los almacenes porque la indiada, al no tener qué comer, optará a no dudarlo por proveerse por la fuerza... la población esperaba hoy, ansiosa, la llegada de tropas del ejército..." Último momento: Acaba de llegar un contingente de indios cargados de latas de café, cuchillo, azúcar, harinas, alpargatas. Se ha sabido que ello es producto del asalto a los almacenes de los Lotes Enrique, Florencia y San Antonio".

(Del corresponsal de "La Opinión" en Ledesma. La Opinión, 12 de febrero de 1946).

\section{Escena III}

“El problema mayor (...) fue el que atravesaron dos censistas enviadas al Ingenio Ledesma en 1966 (...) cuando Arrieta, propietario del ingenio, presionó (...) para que a la población kolla que vivía en el ingenio Ledesma se la discriminara de los matacos y guaraníes para no censarla. Los problemas comenzaron cuando los administradores del ingenio las denunciaron por "hacer preguntas comunistas". En realidad, la "pregunta comunista" era aquella que inquiría: "En el caso de tener un día mucha plata, ¿qué haría usted con ella?". Esta pregunta tenía su razón de ser en el marco del interés que los diseñadores del censo mantenían por los procesos de "aculturación". La respuesta unánime de los censados, que irritaba tanto a los Arrieta, era que de contar con los recursos necesarios, comprarían un terreno para dejar el ingenio y obtener su independencia económica y personal".

(LENTON, 2003, p.201). 
A lo largo de la historia en el Noroeste Argentino (de aquí en más NOA) ${ }^{1}$ la relación entre pobladores campesinos, indígenas y posteriormente obreros, frente a patrones y empresas, ha sido, de constantes sometimientos, enfrentamientos y represiones. ${ }^{2}$ Una de las características más marcantes, y me voy a referir ahora específicamente a Jujuy, fue la dependencia y subordinación de las fuerzas represivas (policía y gendarmería) a los intereses de las elites económicas y políticas locales. Así, ingenios azucareros y minas usaron (y usan) a estas fuerzas del Estado, como un brazo más de sus empresas. Los poderes coercitivos del Estado pasaban y pasan a ser los poderes represivos de los señores locales, generando una verdadera y perversa simbiosis entre el poder político e instancias privadas de las elites

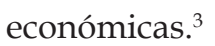

Estas relaciones son recordadas por Avelino Bazán ${ }^{4}$ en relación al día que su familia fue expulsada de la mina Aguilar, frente a una discusión de su hermana con la esposa del gerente,

“Era una noche fría, oscura y donde no conocíamos a nadie. Aún ahora siento el frío y la desesperación de esa noche. No era de

\footnotetext{
${ }^{1}$ El Noroeste Argentina es la región de Argentina comprendida por las provincias Jujuy, Salta, Catamarca, La Rioja, Tucumán y Santiago del Estero. Es una de las zonas de mayor presencia indígena del país, con ciudades que mantienen sus trazos coloniales y prácticas culturales, musicales y sociales característica de la zona andina.

${ }^{2}$ Sobre los conflictos y formas de regulación de las relaciones hay trabajos ya clásicos para el NOA, podemos citar a Craviotti, Clara (1992); Karasik Gabriela (1994); Isla, Alejandro (1992) e Isla, Alejandro y Julie Taylor (1995).

${ }^{3}$ Como bien apunta Kindgard (2001), en su trabajo sobre el peronismo en Jujuy, para poder entender esta particular simbiosis, hay que observar cómo queda cristalizada en la directa y apabullante injerencia de los "intereses azucareros en las estructuras del sistema político provincial, que reside en el especial interés que demostraron los industriales azucareros por influir en los centros mismos de la toma de decisiones, delineando las pautas de la política estatal en materia impositiva, laboral y de administración de los sistemas de irrigación, aspectos considerados de vital importancia pata la maximización de las ganancias del sector" (KINDGARD, 2001).

${ }^{4}$ Avelino Bazán desapareció, en manos de las Fuerzas Armadas, en 1978. Fue el principal referente del Sindicato Obrero Mina El Aguilar (SOMA). En 1958 había sido elegido secretario gremial del SOMA. En 1965 renunció a la mina y en 1966 fue electo diputado provincial y luego director municipal de Trabajo. A seguir comenzó a trabajar en la Dirección de Trabajo de San Salvador de Jujuy. En 1972, sus antiguos compañeros de la mina se rebelaron contra los patrones, el evento se conoció como "El Aguilarazo". El 29 de marzo de 1976 fue secuestrado por primera vez y estuvo detenido hasta junio de 1978. El 28 de octubre de 1978 lo vuelven a secuestrar y desde ese momento está desaparecido.
} 
extrañar el trato que mi familia había recibido, después supe que era habitual ese tipo de procedimientos para con el personal que se revelaba contra las disposiciones de la empresa, las cuales la policía se encargaba de hacerlas cumplir al pie de la letra, sea con el calabozo o a rebencazos. No eran pocos los que solíamos oír los gritos de dolor que se lanzaban desde dentro de la comisaría". (BAZÁN, 2011, p.25).

Las escenas del pasado, arriba relatadas, nos llevan a dos regiones de Jujuy: la Puna y el Ramal. Si nos trasladamos a la actualidad, en estas mismas zonas, esos acontecimientos no constituyen algo olvidado o silenciado, sino que pueden ser rastreados en el lenguaje cotidiano, en las representaciones que circulan sobre el comunismo y en las violencias físicas y simbólicas ejercidas por las elites económicas locales. Dan cuenta de una larga historia de violencia y represión, pero también de revueltas y luchas en la región.

En este texto me interesa plantear las relaciones y diferencias entre dos planos de análisis. Por un lado, la temporalidad de las memorias locales. Estas desplazan su construcción fuera del marco de las miradas dominantes que las posicionan a partir de la dictadura militar del 24 de marzo de 1976. Este trabajo sobre el pasado distingue en dos tiempos, las memorias largas y las memorias cortas. ${ }^{5}$ Por otro lado, se observará la tensión que surge de los relatos al poner en juego el testimonio oral frente al dominio de lo establecido por la escritura. Esta manera de mirar el pasado, desde las tensiones generadas por memorias locales sobre las memorias más encuadradas, permite descubrir las resistencias y estrategias de aquellos que portan menos capitales económicos y simbólicos para imponer sus relatos en el espacio público.

En las localidades de Tumbaya y Calilegua, ${ }^{6}$ es posible mirar los

\footnotetext{
${ }^{5}$ Si bien fue el propio trabajo de campo el que me llevó a formular la relación entre memorias largas y cortas, posteriormente accedí al trabajo de Silvia Rivera Cusicanqui (2010), que discute la relación entre memorias largas y memorias cortas en relación a las luchas campesinas Aymara y Quechwa en territorio boliviano. En su análisis se refiere a la memoria corta, en relación a la insurrección popular de 1952 que marcó la Reforma Agraria y a la memoria larga, para dar cuenta de las luchas indígenas anticoloniales.

${ }^{6}$ Calilegua y Tumbaya son dos pequeñas localidades de Jujuy. Calilegua está situada en la zona de las Yungas y pertenece a lo que se conoce como el Ramal. Es el pueblo dónde originalmente estaba localizada la "Sala" casa del Ingenio Azucarero, hoy conocido como "Empresa Ledesma". Tumbaya, está localizada en el inicio de la Quebrada de Humahuaca. Durante la década del setenta en ambas localidades hubo diversos episodios de represión. En la zona del Ramal, más específicamente en Calilegua y Libertador General San Martín en 1974,
} 
contrastes que se producen con las representaciones y prácticas dominantes en torno a las violaciones a los derechos humanos y la memoria de la represión, que con su léxico y formas particulares de hablar de la violencia restringen a ésta a un período corto (1976-1983), con actores generalmente definidos en torno a las fuerzas represivas del Estado (FFAA, policía y gendarmería), y terminan por imponer formas de dominación simbólica sobre qué y cómo debe recordarse el pasado. Operan de alguna forma dejando de lado períodos más largos y complejos en relación a las vivencias de violencia y su memoria y a otros actores involucrados en ellas. Cuando me refiero a las representaciones y prácticas dominantes en torno a las violaciones a los derechos humanos, estoy pensando en los discursos cristalizados y los relatos dominantes que emanan tanto del Estado nacional y sus políticas de memoria (desde el Nunca Más a las innúmeras manifestaciones actuales desde el ámbito de la educación a proyectos como el Archivo Nacional de la Memoria o el Museo de la Memoria) como de los organismos de derechos humanos que desde Buenos Aires imprimen modelos para pensar el pasado y su violencia.

En las formas que adquiere la construcción de las memorias no se ubica, en este contexto territorial, a la última dictadura militar como una "modificación" en los regímenes de violencia, sino más bien como un episodio, con sentido variable, de modos de producción y circulación de la violencia simbólica y física que se corresponden con estados anteriores (y también actuales) de la configuración social, política y económica de la región. Dentro de esta configuración, lo que se comprende, al incorporar en el análisis a las memorias largas, entre otras cosas, es que la violencia no es observada ni pensada como un episodio pasajero u extraordinario, sino constituyente y constitutivo de las relaciones políticas, sociales y económicas de la región.

400 personas fueron detenidas y encarceladas, principalmente sindicalistas y adherentes que protestaban contra las condiciones de trabajo en la Empresa Ledesma. Luego en julio de 1976 se produjo el episodio de represión conocido como Apagón de Ledesma, donde en una noche se cortaron las luces de Calilegua y fueron detenidas 30 personas, 10 de las cuales permanecen desaparecidas. En Tumbaya, durante el año 1976 se produjeron tres episodios de secuestros, en uno de ellos se secuestraron 20 hombres, todos afiliados al Partido Comunista, seis de los cuales permanecen desaparecidos. Tumbaya contaba en ese momento con 150 habitantes. 


\section{Violencia, memoria y derechos humanos: continuidad e incorporación.}

Cuando comencé mi trabajo de campo en Jujuy, ${ }^{7}$ más específicamente en Calilegua, muchos aspectos me sorprendieron. Entre aquellos que me provocaron una mayor reflexividad, estuvieron los relativos a las diferentes maneras en que se producían y transmitían los relatos sobre el pasado reciente. Habituada a realizar entrevistas con familiares de desaparecidos en las grandes ciudades o con ex presos y militantes políticos de La Plata (Da Silva catela, 2001), me llevó un tiempo comprender que existían otros sistemas de clasificaciones que no se correspondían con las maneras de construcción de las memorias sobre la represión tantas veces escuchadas. ¿Cómo podía ser, por ejemplo, que en este contexto de tanta represión, la palabra centro clandestino de detención no hiciera ningún sentido a aquellos que habían pasado por ellos?

Hubo dos ejercicios en el trabajo de campo que funcionaron como indicios en relación a la presencia de las memorias cortas y largas. Por un lado, al releer las entrevistas realizadas comencé a percibir cómo, frente a mis preguntas sobre la dictadura militar, las personas de Calilegua y Tumbaya, sobre todo aquellas que habían estado presos, concentraban el relato en períodos anteriores y no usaban el año 1976 o el 24 de marzo como un marco de quiebre o de referencia. A decir verdad en la mayoría de las entrevistas no se habla de esta fecha ni se enuncia el golpe de Estado. El segundo elemento importante fue el trabajo de campo en Tumbaya. Allí

\footnotetext{
${ }^{7}$ En el año 2000 comencé mi trabajo de campo en Jujuy, más específicamente en Calilegua y a continuación en Tumbaya. El mismo se prolongó hasta el año 2008 y fue retomado en el año 2016. El objetivo central de la etnografía en la zona, fue relevar y analizar las memorias locales ligadas a familiares de desaparecidos cuyos seres queridos habían trabajado en el Ingenio Azucarero de Ledesma y en la Mina de Tumbaya. En mis estadías realicé observación participante de actos y rituales, entrevistas y registros visuales con los familiares de desaparecidos y con ex presos y presas políticas, charlas con los vecinos, recolección de documentos de archivos personales, relevamiento de fuentes históricas y de diarios y revistas de la zona. También entrevisté a referentes políticos de Jujuy que participaban de los actos relativos a las memorias de los desaparecidos de la región y a abogados que llevaban las causas de juicios de lesa humanidad en relación a la represión en estas dos poblaciones. Al trabajar con memorias locales, el trabajo de campo, me permitió desarmar las categorías consagradas de las memorias centrales para generar una mirada crítica sobre las concepciones dominantes y los marcos temporales establecidos para pensar el pasado reciente en Argentina.
} 
comprendí que las experiencias de vivencias frente a la violencia y la desaparición de personas planteaban componentes diferenciales entre la ciudad y los pueblos; entre las memorias dominantes y las subterráneas; entre las formas del relato y la pertenencia a clases sociales diferentes y principalmente una clara continuidad en el tiempo en relación a las violencias vividas. Había así una tensa relación entre las memorias largas y las memorias cortas, entre los ejercicios de recuerdos encuadrados por los relatos oficiales (cristalizadas por ejemplo en el Nunca Más o en las políticas de memorias del Estado que recorta claramente el horror a partir de 1976) y otros subterráneos y encuadrados por esquemas culturales tradicionales, que no se restringen solamente a las referencias de la última dictadura.

Por comparación, se puede analizar como muchas palabras, que yo misma había naturalizado, como Centro Clandestino de Detención (CCD), desaparecidos, tortura, terrorismo de Estado, no significaban nada o cosas muy disímiles a las que había registrado por años en mis otros trabajos de campo, nacidas y consagradas por las memorias de la represión que circulan, sobre todo, en las grandes ciudades en Argentina. Por otro lado, palabras como subversión, terroristas, que raramente eran enunciadas entre los familiares de desaparecidos de La Plata a no ser para hacer referencia al tipo de clasificación de los propios militares, entre los familiares de desaparecidos de Tumbaya y Calilegua, eran corrientes para clasificar o acusar a los "otros", a los "culpables".

El discurso que se enhebra sobre los derechos humanos en la Argentina actual remite a un lenguaje nuevo e incorporado que generalmente da cuenta de una memoria de la represión "corta" centralizada en los episodios de los años 70, controlada y encuadrada en una serie de clasificaciones y sentidos sobre lo que se puede decir, lo que se debe decir y lo que no y sobre todo, con el aprendizaje y la incorporación de una serie de "nuevas palabras" que delimitan claramente este período represivo de otros, pero que requieren además de destrezas lingüísticas y de capitales culturales, simbólicos y políticos para poder expresarlas públicamente. Sin embargo aquellos que pasaron por episodios de violencias (uso el plural para dar cuenta de diversas violencias vividas) arrastran el uso de otras palabras y representaciones para expresar sus vivencias frente a las violencias. Gerónimo Lamas, quien fue secuestrado en Tumbaya en 1976 y permaneció preso por un año en diversas dependencias del Estado, relata lo siguiente. 
G: Pero lo criminalista (para referirse a "lo criminal") ha sido que se me ha agarrado, se me ha tomado, ¿no?... Porque es lo que he estado casi un año preso, en la casa de detención, totalmente incomunicado, durísimo, triste y sólo como dicen, en una celda, sólo, tan sólo era lugar que ni podía salir al baño... Nos apaleaban, nos tiraban al suelo como troncos, sin un lugar donde poder hacer las necesidades. Y lo peor, lo peor fue... recibir la comida como un perrito, fría o caliente, como un perro.

(Entrevista, 25 de julio de 2004).

"Ser apaleado", "tratado como un perro", "tirado al suelo como un tronco" no significa, lo mismo que torturado, simplemente porque entre aquellos que me lo relataban, este tipo de violencia sufrida sobre el cuerpo no se inició en 1976 (como bien demuestra Bazán en su relato sobre los rebencazos, en un contexto previo no dictatorial), ni terminó en 1983. Las nociones más generales sobre la violencia sufrida en carne propia e infringida por parte de las elites locales sobre los cuerpos de campesinos y obreros de la región, dan cuenta de memorias de la represión más "largas", con rupturas temporarias que no tienen que ver con dictaduras o democracias, sino con conflictos locales y ejercicio de las violencias por parte de aquellos que controlan el poder y la disciplina en relación a las fuentes de trabajo y el dominio político. ${ }^{8}$ Lo que me interesa remarcar es que en los relatos sobre la dictadura o los testimonios de cómo eran tratados en sus lugares de trabajo, no hay discontinuidad en relación a la violencia sufrida. Es interesante que cuando indago a Ávalos, un obrero de la mina de Tumbaya, sobre la situación vivida frente a la policía que lo secuestró en 1976, él traza un rápido nexo con las relaciones conflictivas y previas a la dictadura con el capataz de la Mina.

L: La policía lo acusaba de qué, ¿de montonero o de comunista?

E: De comunismo, de... "usted era del comunismo", "usted tiene armas" me decían. ¿Para qué? Nada, no han sacado y no nos han comprobado nada, absolutamente nada porque no éramos

\footnotetext{
${ }^{8}$ Sólo a modo de ejemplo en el año 2004 en Tumbaya fue asesinado a golpes, por enfrentamientos políticos entre radicales contra peronistas, un joven del lugar. Inicialmente la muerte fue caratulada como "suicidio", siendo que todo el pueblo sabía que hubo cuestiones políticas en el asesinato. Luego de muchas marchas y demandas por parte de los familiares, los asesinos (todos conocidos del muerto) fueron presos.
} 
nada... Tan sólo por defender la clase obrera, más por eso, y más porque Carlos Jeczmieniowski fue el que nos denunció, él era comisionado municipal. Y cómo yo los defendía a los obreros, cuando él era capataz de la mina, él tenía rabia con eso. Era terrible trabajar en la mina: ni la ropa nos daba, no nos pagaban el salario, nos trataban como a animales. Por eso digo, ellos tenían que llevarse directamente a Carlos Jeczmieniowski adentro, porque él ha usurpado mucho con los obreros, no nos ha pagado las horas, no nos han dado la ropa. Exactamente hemos trabajado diez horas y no nos ha dado ni una horita de descanso, al menos. Es decir, era este hombre el que tenía que estar bien guardado y no nosotros. Después nos llevan a Humahuaca, me han pisoneado, me han metido las armas por la espalda, nos han tirado al suelo, nos ha andado pisoneando. Hijos de puta!, nos decían. ¡Pisando la espalda! Pero ha sido una injusticia. Todo injusto.

(Entrevista trabajo de campo, 24 de julio de 2004).

En varios de los relatos, indagué si habían sido torturados, a los que me respondieron que no. Luego comparando las entrevistas, percibí que esa palabra no hacía mucho sentido en estos contextos. Don Narvaes, ex obrero y gremialista en la Empresa Ledesma, preso en 1976 en Guerrero, en medio de su relato me dice:

"...Después nos sacaron y nos metieron adentro en piezas, calabozos, no sé bien por qué no he podido ver y ahí me han tenido 10 días. Esa tarde, esa noche misma me han metido un golpe, porque al que se le corría la venda o se le aflojaba tenía que avisar, se le ha corrido y se le ha salido la venda y bueno serían como las 2 de la tarde -uno se daba cuenta porque ahí tenían la radio prendida- entonces yo llamo y le digo: "guardia, se me bajó la venda" "bueno ya va" contestaban, al rato cayó. Porque si no avisaban lo sorprendían y le daban una paliza, como le llaman a esto cuando los apalean... represión

\section{- Ludmila: Lo torturan}

- Don Narvaes: Tortura, eso exactamente y había que avisar porque si no ya lo aporreaban. Bueno yo le aviso y entonces dice el tipo "a quién se le salió" y nosotros estábamos tirados así boca abajo, agarro me levanto y digo "a mí". "No mire, hijo de puta -dice- Agachate" y me han levantado y me la han atado. Y me han dejado ahí y al rato vuelve "¿no tenés ganas de orinar?" "sí" le digo, "vení vamos al baño" me dice y me agarra de aquí y me 
ha levantado a los tropezones, porque todos los otros compañeros estaban tirados ahí como troncos.

(Entrevista trabajo de campo, 21 de julio de 2001).

Hay un punto central, que me gustaría resaltar y se refiere a los límites entre el trato humano y no humano. Más allá de los discursos construidos o de las definiciones normativas sobre lo que sea una violación a los derechos humanos, lo que Don Gerónimo y Don Ávalos, y la mayoría de los entrevistados, afirman es que lo trataron como a perros, cómo animales, los deshumanizaron en nombre de la traición a la Patria, pero también y sistemáticamente, en las relaciones de trabajo en la mina y en el ingenio. La noción de ser "apaleados" o "azotados" con rebenques (los cuales se usan para los caballos) aparece en todos los relatos de los que estuvieron presos y es la imagen más elocuente sobre la animalización de sus cuerpos.

Las metáforas en relación a la animalización de los cuerpos expuestos a la violencia nos desafía a pensar los procesos de alteridad que se ponen en juego y que nos remiten a un sistema de símbolos que cruza la idea de la nación Argentina, en la consigna civilización y barbarie. ${ }^{9}$ Salvajes, indios, subversivos, comunistas, parecen conformar una línea que no debe cruzarse frente a la civilización y la "buena sociedad", que usa los mecanismos represivos como medio de regular esa frontera, animalizando al "otro" con mecanismos de minimización, lo que posibilita su destrucción y consumo simbólico (URIBE ALARCÓN, 2004).

La imposición de discursos y la utilización de las categorías nacidas en relación a la lucha por los derechos humanos violados a partir de 1976, puede reducir las memorias a un capital político intercambiable y aplicable a todos los contextos sin tonalidades ni diferencias, dejando de lado $\mathrm{u}$ opacando memorias más complejas, cargadas de tonalidades y zonas grises.

\section{Violencia y represión: el lugar del Estado y de las élites locales.}

La violencia ejercida por las elites locales y la violación a los derechos humanos provocada por el terrorismo de Estado de la última dictadura

\footnotetext{
${ }^{9}$ La noción de civilización o barbarie es constitutiva de la conformación de la nación Argentina. La obra que tematizo esta oposición fue "El Matadero", escrito por Esteban Echeverría entre 1838-1840.
} 
militar, son eventos diversos, sin embargo en contextos locales como Calilegua, Tumbaya, pueden observarse como una continuidad y no como una ruptura.

Una característica que se repite y constituye un indicio fuerte, es que el Estado raramente se enuncia como aquel que protagonizó la violencia o es culpable de lo que pasó. Contrariamente, son los "patrones": la Empresa Ledesma o el interventor que era el gerente de la mina de Tumbaya, los que aparecen una y otra vez como los causantes de las desapariciones y la violencia de la última dictadura militar. Así, la violencia sufrida es localizada con nombre y apellido y puede ser visitada y revisitada a lo largo de una historia que no es contada linealmente, ni por períodos históricos determinados, ni a partir de un sólo tipo de relato.

La cuestión es que el Estado, sobre todo en el caso de Calilegua y Tumbaya, está al servicio de las elites económicas locales. La gendarmería y la policía están situadas al lado del Ingenio y en la Mina, en el discurso y las prácticas no se diferencian de la "empresa". La intervención en Tumbaya fue vivida como una continuación de la difícil relación con el capataz de la Mina y no como una acción del Estado. Así, me interesa resaltar, por un lado el uso de la violencia por parte de las elites locales como un continuum en la regulación de las relaciones sociales y cómo ha quedado registrada en las memorias comunitarias la idea que todo el pueblo ha sido estigmatizado con la imagen de un lugar peligroso: Tumbaya fue bautizado por el interventor militar como la "Tucumán chiquita" y Calilegua fue tildada de "pueblo subversivo". Me cuenta Gerónimo, una historia que es repetida por cada uno de los entrevistados:

Jeczmieniowski, que fue el capataz de la mina y luego el interventor en Tumbaya, y le ha puesto el nombre de Tucumán chiquito, así le decían a Tumbaya. Claro, porque él decía que se había arriado la bandera del Partido Comunista acá en Tumbaya, que habíamos izado nosotros, y nosotros nunca la habíamos izado. Pero él lo dijo en un discurso, que aquí se había arriado la bandera del partido Comunista. Y fue él el que ha entregado a los changos, él los ha entregado. Era capataz, administrador de la mina, la empresa de Romero \{actual gobernador de la provincia de Salta\}. Él fue quien los entregó.

(Entrevista trabajo de campo, 25 de julio de 2004 y 23 de julio de 2005). 
En relación al Apagón de Calilegua Ángela Córdoba, hermana de dos desaparecidos, reflexiona:

Fue una noche muy triste, prácticamente a Calilegua como que le pusieron tinta roja como pueblo guerrillero, porque hasta el año pasado, recién creo que lo sacaron ahora, estaba con lápiz rojo, adentro de la misma municipalidad Calilegua como pueblo subversivo.

(Entrevista trabajo de campo, 24 de julio de 2004)

Si volvemos a las escenas con las que inicié este texto, vemos que un siglo después de la revuelta en la tierras de la puna jujeña, nuevamente el poder local, con sus representantes en el Estado, acusa a todo un pueblo de comunista y treinta años después de la primera gran huelga realizada a al Ingenio Azucarero de la Empresa Ledesma se marca a Calilegua, no ya como un bando de indios salvajes, sino como a un pueblo subversivo, guerrillero. Tanto el ser tachado de comunista, como de guerrillero, tuvo altos costos para aquellos que se vieron tocados por estas "marcas". Ningún familiar de desaparecido de Calilegua, por lo menos hasta que terminé mi trabajo de campo, había conseguido trabajo en la Empresa Ledesma y, con el retorno de la cárcel, los presos de Tumbaya que trabajaban en la municipalidad, no lograron retornar a sus lugares de trabajo o al ser echados de la mina no consiguieron que se les pague una indemnización.

\section{Los juicios: la tensión entre la tradición oral y el documento escrito.}

En el año 2011 fui llamada a testimoniar en el juicio de lesa humanidad que se llevaba adelante en Jujuy. Durante el trabajo de campo había entrevistado, desgravado las entrevistas, filmado y entregado las copias de las mismas a cada uno, pero persistía la demanda para que escriba un libro.

Tanto don Federico como don Gerónimo, en diversas oportunidades me dijeron: "Usted tiene que escribir la historia de lo que pasó en Tumbaya". Cómo antropóloga, escribí algunos textos, que publiqué en territorios exóticos para la comunidad, artículos analíticos y distanciados, críticos y enredados en las lógicas de la academia. Se los llevé, los miraron y volvieron a repetir: "tiene que escribir un libro Ludmila, la historia". En ese momento no comprendí la importancia y el peso de la noción de HISTORIA que me demandaban. 
Cuando fui llamada como Testigo de Contexto, entre las diversas causas que se acumularon estaba la de Tumbaya. Este mecanismo de los testigos de contexto es una práctica muy común en los juicios en Argentina, en general cumplen este rol historiadores con sus libros o periodistas con sus investigaciones. Muchas veces ante la falta de documentos funcionan como legitimadores de un discurso que garantiza fidelidad de los hechos, como si la confianza estuviera puesta en los signos externos de la escritura, aunque mayoritariamente lo que han hecho fue volver en libros las mismas entrevistas que los jueces han escuchado de los testigos. Cuando la querella me convocó como testigo, me explicaron que los testigos de Tumbaya "habían hablado poco", que sus intervenciones se habían resumido a respuestas breves y que pocos habían contado sus experiencias de secuestro. Durante mi intervención relaté lo que conocía sobre Tumbaya, pero sobre todo ofrecí las más de 50 horas de entrevistas que tenía, para lo cual me fue demandado por parte de los defensores que explique la metodología de trabajo y la intención con la cual las había realizado. Finalmente el tribunal me preguntó: "usted escribió un libro de historia con las entrevistas". Mi respuesta fue que tenía todas las entrevistas desgravadas, que había escrito artículos, etc. Pero el tribunal denegó la posibilidad de aportarlas como prueba por que no tenían rigurosidad histórica: No estaban publicadas.

Este episodio permite comprender las nociones variantes y las relaciones de poder cuando se utilizan las nociones de memoria o de historia para validar o denegar las experiencias en torno al pasado. La justicia, como espacio de poder y portadora de un positivismo ingenuo, cargó de valor a la HISTORIA pensada como un LIBRO donde ésta puede fijarse y registrarse objetiva y exhaustivamente y en el mismo acto desestimó a la memoria por peligrosa y subjetiva. En ese momento comprendí profundamente los pedidos de don Gerónimo y don Federico, sabedores de que el valor de sus palabras, de su tradición oral, de sus experiencias y saberes podía validarse en su comunidad pero que perdían eficacia y poder fuera de ella, que la HISTORIA debía ser traducida en un LIBRO. Con sus pedido se estaban anticipando a las acciones que pesarían sobre sus dichos, inestables, inseguros, pero también estratégicos en función del miedo que pesa sobre sus vidas aún hoy. Un libro de historia hubiera validado sus escasos capitales políticos y simbólicos en la esfera pública, hubiera tornado sus palabras, porque como dice Jak Goody: 
“...todo documento tiene en sí un carácter de monumento y no existe una memoria colectiva bruta. En este tipo de documento la escritura tiene dos funciones principales: «Una es el golpe imprevisto de la información, que consiste en comunicar a través del tiempo y del espacio, y que procura al hombre un sistema de marcación, de memorización y de registro», mientras la otra, «asegurando el pasaje de la esfera auditiva a la visual», consiste en permitir «reexaminar, disponer de otro modo a la memoria". (GOODY, 1996, pág. 78).

En el extremo este caso muestra que aquellos que fueron "negados" por siglos por LA HISTORIA - los indígenas- fueron también doblemente desaparecidos. Por un lado, la obra totémica por excelencia en Argentina, el Informe Nunca Más, no los incluyó en su relato y cuarenta años después demandan esta visibilidad y lo hacen en nombre de ser incluidos en el relato de la nación. Por otro lado, sus memorias subterráneas permanecieron intactas, pero para poder validarlas necesitan el reconocimiento y la posibilidad de pertenecer al mundo que circula y se visibiliza a través de las letras, que otorga poder por medio de los libros y que se transforma en verdad por la Historia. O sea, para decirlo con otras palabras, aquella que legitimó y cristalizó a las memorias encuadradas y dominantes centradas en la violencia del mundo urbano, con una temporalidad histórica determinada y con eventos del pasado conocidos y validados en el espacio público.

\section{Tensiones finales}

En este artículo he perseguido los aprendizajes conseguidos durante el trabajo de campo, en torno a las memorias locales y en el mismo giro, el cuestionamiento a las categorías consagradas de oralidad y escritura; historia y memoria; memorias largas y memorias cortas. En una y otra instancia, me interesó comprender las diversas conceptualizaciones nativas en torno a sus vivencias y experiencias de violencia política.

Durante el trabajo de campo tuve que girar la mirada, en diversas oportunidades, para repensar una y otra vez algunos ejes que aparecían como demasiado cristalizados y sacralizados. Por un lado, la noción de verdad/verdades y por otro, la multiplicidad de temporalidades que se presentaban. Las respuestas a mis preguntas por parte de los hombres y mujeres con los que interactúe, me hicieron volver a mirar con lupas las categorías teóricas consagradas de memoria e historia. 
Los estudios de memoria, en general, afirman y dan cuenta de la importancia de la reconstrucción del pasado para su uso político en el presente, frente a la necesidad de soportar los dolores y los traumas nascidos de las situaciones extremas vividas. En menor medida, se cuestionan sobre el impacto que los trabajos de las ciencias sociales generan en los contextos locales, donde esas memorias se traducen en testimonios, actos y rituales. El trabajo de campo en territorio jujeño, permitió abrir nuevos niveles de percepción sobre los modos de construcción de las memorias. Ya no centradas en una temporalidad histórica corta, ligada al pasado reciente, sino a múltiples tiempos donde los cuerpos fueron violentados más allá de los marcos coyunturales de democracias o dictaduras. Un tiempo largo, que da cuenta de diversas formas de represión desde el Estado o desde las élites económicas locales. Por otro lado, si bien como etnógrafa fui formada para estar atenta a los múltiples sentidos sobre el pasado, al momento de traducir esto en formato determinado y en espacios particulares, pasé a instituir una verdad, construí una visión que, en el extremo, puede ser leída como única. De allí que el intercambio de puntos de vista con quienes interactué en el campo, me permitieron comprender las formas variables de pensar las nociones de memoria e historia.

También, permite cuestionar y revisitar esos conceptos instalados en el canon de los clásicos y llevar al extremo las nociones que reproducimos una y otra vez en nuestros papers. La tensión entre historia y memoria muestra un espacio de inscripción que necesita ser completado e impreso con significados una y otra vez. Es justamente sobre la superficie de las memorias locales, donde se da cuenta de este lugar de inscripción diverso, conflictivo, creativo. Permite mostrar otros tiempos, intercambiando una y otra vez el sentido de los conceptos de historia y memoria en relación a las narrativas orales o a las demandas de su escritura. En el mismo juego, es la experiencia etnográfica, el encuentro con el "otro" lo que me permitió observar que las memorias pueden o no ser liberadoras; que la Historia puede o no ser sinónimo de opresión. Permitieron ver con claridad la relatividad de estos conceptos muchas veces sacralizados en los estudios y perspectivas teóricas consagradas. De la misma forma, la relación entre oralidad y escritura, pudo ser observada como complementaria, donde la escritura y más específicamente los libros pasan a ser un territorio de demanda legítima por parte de los grupos con los cuales trabajé. Los libros son pensados como espacios de inscripción contra el olvido y lugares de memoria donde pueden legitimarse sus relatos subterráneos y muchas 
veces denegados, sobre todo en aquellos grupos que necesitan imponer sus experiencias "marginales" (como las indígenas) para que sean audibles e incluidas desde su valor de experiencias y saberes.

\section{Referencias}

BAZAN, Amelino,

(2011) El porqué de mi lucha. 30 años en la vida gremial del pueblo aguilareño. Colección Memoria en Movimiento. Buenos Aires, Secretaria de Derechos Humanos de la Nación.

CRAVIOTI, Clara.

(1992). Azúcary conflictos en el Norte argentino. Buenos Aires, Centro Editor de América Latina.

DA SILVA CATELA, Ludmila.

(2001). No habrá flores en la tumba del pasado. Las experiencias de reconstrucción del mundo de los familiares de desaparecidos en Argentina. La Plata, Editorial Al Margen.

GOODY, JACK

(1996). Cultura escrita en sociedades tradicionales. Buenos Aires, Gedisa.

ISLA, Alejandro.

(1992). Sociedad y articulación en las tierras altas jujeñas. Crisis Terminal de un modelo de desarrollo. Buenos Aires, Asal / MLAL.

ISLA, Alejandro; TAYLOR, Julie.

(1995). Transformaciones y fragmentación de identidades bajo el terror en el Noroeste Argentino. En Revista Andina, año 13, n². Cusco. Perú.

KARASIK, Gabriela.

(1994). Cultura e identidad en el Noroeste Argentino. Buenos Aires: Centro Editor de América Latina.
KINDGARD, Adriana.

(2001). Los orígenes del peronismo jujeño. Jujuy, UNJU.

LAPIERRE, Nicole

(1989). Le silence de la mémoire. Paris, Éditions Plon.

LENTON, DIANA.

(2003). Todos éramos desarrollistas. La experiencia del primer censo indígena nacional. Revista Etnía , 46-47, 187-210.

URIBE ALARCON, María Victoria.

(2004). Antropología de la inhumanidad. Un ensayo interpretativo sobre el terror en Colombia. Grupo Norma Editorial.

RIVERA CUSICANQUI, Silvia.

(2010). Oprimidos pero no vencidos. Luchas del campesinado campesino Aymara y Qhechwa. 1900-1980. La Paz, La Mirada Salvaje.

RUTLEGDE, I.

(1992). La rebelión de los campesinos indígenas de las tierras Altas del Norte Argentino. En: Alejandro Isla; Sociedad y articulación en las tierras altas jujeñas. Crisis Terminal de un modelo de desarrollo. Buenos Aires, Asal / MLAL.

\section{Recebido em}

setembro de 2016

\section{Aprovado em}

março de 2017 